\title{
The Problem of Helio-Gerontology: The New Scientific Point of View at the Processes of Aging and Water-Holographic Prevention
}

\author{
Alexander Trofimov \\ Department of Biophysics, International Scientific-Research Institute of Cosmic Anthropoecology, Novosibirsk 630090, Russia
}

\begin{abstract}
The author's hypothesis for amount of the solar activity during prenatal development of human organism, detecting gene expression responsible for the level of metabolism and the fact that age processes can restrict man lifespan was investigated. The prenatal period of each person development proceeds in continuous interaction with heliogeophysical environment, depending on individual helio-magnetosensitivity of an organism. Heliogeophysical impact was estimated with the use computer program HELIOS (Ru Reg.Cert. 970125, 24.08.1997). There was a task in view: to develop new generation of helio-protectory means for people with high heliosensitivity and high risk of accelerated aging. Such means were created and patented in Russia (patent RU 2342149, 27.12.2008) and they were named helio-geroprotectors. Tests on bio-objects have shown high efficiency of such protectors on water and-holographic basic, increase in level steroid hormones, anabolic processes and reduction of speed of aging estimated on relation of stable isotopes of carbon 13C/12C in tissues (wool) in males-rats $(n=30)$, born at high activity of the Sun and using special informational light-hologram (patent RU 2239860, 10.11.2004) or for drink within one month water helio-protectors. Change of the level of isotope 13C in tissues (hairs), which content was detected by mass-spectrometer Delta and the vector of correlation of the decreasing or increasing of this isotope with sun's protons streams may be a new marker of rate of human aging and criteria of helio-gero-protectors efficiency. New helio-biophysical horizons of non-medical decrease in rate of human aging are designated.
\end{abstract}

Key words: Helio-geophysical factors, prenatal ontogenesis, water-holographic gero-prevention.

\section{Introduction}

At the 6th European Congress of International Association of Gerontology (2007) for the first time we designated helio-biophysical aspects of geriatrics. Significant differences in mean values of solar activity (Wolf number, W) were shown on the 8th month of prenatal development in the persons 30-70 years old as compared with the group of the elderly people of 71-90 years old. Thus, it was shown that the most favorable situation for long living arises in such cases when the prenatal ontogenesis runs in conditions of minor solar activity. It is supposed that rate of organism aging in case controversial helio-physical situation (high solar activity) may increase man lifespan restrictions [1-4].

Corresponding author: Alexander Trofimov, Ph.D., professor, research field: Geoecology. E-mail: isrica2@rambler.ru.
The main goal of this investigation was to describe morphofunctional picture of the changes occurring in the body of animals during test information holograms of a new type and treated water, as well as the dynamics of bio-helio-geophysical integration of the animal's organism in the course of the experiment. Scheme of the experiment on rats Vistar is provided for the presence of a control group of animals ( $n=10$ ), which do not suffer direct and indirect information-holographic impacts and are held at a considerable distance $(6.0 \mathrm{~m})$ from the experimental groups. The first group of experimental animals $(n=20)$ used drinking water in the mode ad libitum pre-exposed within 36-48 $\mathrm{h}$ in a container $(5.0 \mathrm{~L})$, coated with aluminum foil on the "window" $(8 \mathrm{~cm} \times$ $15 \mathrm{~cm})$, covered with hormone-active hologram; the 2nd experimental group of animals $(n=20)$ 
experienced a constant distant $(10.0 \mathrm{~cm})$ impact of "hormone-active" holograms placed in plastic Petri dishes on the roofs of wire metal cells. Within 14 hours a day, holograms were illuminated with fluorescent light from a distance of $1.5 \mathrm{~m}$ for 30 days. Hormone-active holograms (the patent of the RF No. 2239860) contained information about the quantum state of testosterone.

\section{Research Design}

The control and experimental-2 groups of animals received in individual bowls tap water from a similar capacity with the "window", closed normal (not an information-intensive) film of the water supply network. Food ration, temperature, lighting, and caring staff were the same for the three groups of animals. The survey was conducted in September-October 2007, the animals were taken under the experimental observation two weeks after receipt from certified nursery and adaptation to the conditions of the experimental laboratory. A month after the beginning of the impacts, the animals were taken out of the experiment. Blood serum was collected and frozen: the mass of the internal organs was measured, AG (adrenal glands) and thyroid were homogenized, centrifuged, and supernatants were frozen for subsequent determination of hormones.

In the process of experimental materials, modern immunoenzyme and radioimmune methods of definition in the blood and tissues of the main hormones were used: testosterone, progesterone, aldosterone, corticosterone, hormones of thyroid gland (T3 and T4). The contents of glucose, cholesterol, triglycerides were measured by enzymatic colorimetric, and urea-by kinetic methods; of animals, internal organs and tissues were measured gravimetrically and the ratio of stable isotopes of carbon (13C/12C) in the hair of animals before and after the experiment was estimated with the use of mass-spectrometer MAT-253 by the company Finnegan (Germany) Biochemical and endocrinological research was carried out by "a double-blind method" under the leadership of D.Sc.
Professor V.G. Selyatickaya.

We used modern packages of statistical data processing with the correlation analysis of the physiological and cosmophysical satellite system GOES parameters in different periods before, during and after the pilot cycle.

\section{Results and Discussion}

\subsection{Influence of Physiologically Active Holograms on the Status of Rats Vistar}

The main object was to explore the contents of steroid and thyroid hormones in blood serum and in the glands of internal secretion. From the Table 1 it follows that the experimental animals, regardless of the type of effects in more than two times increased content in the blood serum testosterone, there is a tendency towards increase of corticosterone.

In the adrenal glands of the 1st animals experimental group, there was a decreased content of aldosterone and improved content of corticosterone, as well as the tendency of progesterone increase, which is reflected in the increase of the amounts of steroids in the adrenal glands in 1.2 times compared with the control rats. In the adrenal glands of the 2nd test animals' group similar changes in the content of aldosterone and corticosterone were only of the nature of trends, however, the level of progesterone in them, on the contrary, has decreased almost in 3 times in comparison with rats of the 1st experimental group. This is also reflected in the overall amount of steroids in the adrenal glands, which in the 2nd animals' experimental group decreased almost in 2 times as compared to the control animals and rats of the 1st experimental group.

The obtained results testify to the fact that in the 1st and the 2nd experimental groups there were effects on hormonal provision of adaptive reactions of the same type according to the final result- the strengthening of adaptive opportunities of an organism with stimulation and plastic, and strange exchange reserves. However, the same final result is achieved in different ways: the 
Table 1 The content of hormones in blood serum of animals of the control and experimental groups (M $\pm \mathbf{m})$.

\begin{tabular}{|c|c|c|c|c|}
\hline \multirow[b]{2}{*}{ Parameter } & \multicolumn{3}{|c|}{ The group of animals } & \multirow{2}{*}{$\begin{array}{l}\text { Statically significant } \\
\text { differences between groups, } P \\
<0.05\end{array}$} \\
\hline & $\begin{array}{l}\text { The 1st } \\
\text { experiment group }\end{array}$ & $\begin{array}{l}\text { The 2nd } \\
\text { experiment group }\end{array}$ & $\begin{array}{l}\text { The control } \\
\text { group }\end{array}$ & \\
\hline (1) Testosterone, $n M / L$ & $10.80 \pm 3.60$ & $12.44 \pm 2.58$ & $4.15 \pm 2.00$ & $2-3$ \\
\hline (2) Aldosterone $\mathrm{ng} / \mathrm{mg}$ in adrenal glands of tissue & $0.39 \pm 0.05$ & $0.42 \pm 0.05$ & $0.52 \pm 0.09$ & $1-3$ \\
\hline (3) Corticosterone, ng/mg in adrenal glands & $7.89 \pm 0.96$ & $6.67 \pm 0.82$ & $4.75 \pm 0.62$ & $1-3$ \\
\hline $\begin{array}{l}\text { (4) Progesterone, ng/mg in adrenal glands of } \\
\text { tissue }\end{array}$ & $10.94 \pm 3.05$ & $3.58 \pm 1.10$ & $9.40 \pm 6.30$ & $1-2$ \\
\hline $\begin{array}{l}\text { (5) The amount of steroids (aldosterone, } \\
\text { corticosterone, progesterone), ng/mg of tissue }\end{array}$ & $18.76 \pm 4.00$ & $9.65 \pm 1.24$ & $15.59 \pm 6.85$ & $1-2$ \\
\hline $\begin{array}{l}\text { (6) The ratio of corticosterone/aldosterone in } \\
\text { adrenal glands }\end{array}$ & $24.0 \pm 3.2$ & $17.8 \pm 2.3$ & $10.5 \pm 1.9$ & $1-3$ \\
\hline $\begin{array}{l}\text { (7) The ratio of progesterone/aldosterone in } \\
\text { adrenal glands }\end{array}$ & $35.6 \pm 10.9$ & $6.9 \pm 1.3$ & $24.8 \pm 18.4$ & $1-2$ \\
\hline (8) T4 in blood nmol/L & $81.62 \pm 6.38$ & $96.29 \pm 4.55$ & $75.40 \pm 5.73$ & $2-3$ \\
\hline (9) T3 in blood nmol/L & $2.68 \pm 0.06$ & $3.31 \pm 0.28$ & $3.45 \pm 0.39$ & $\begin{array}{l}1-2 \\
1-3\end{array}$ \\
\hline
\end{tabular}

animals from the 1st experimental group-stimulation of processes of biosynthesis of steroids in the TM, and the rats of the 2nd experimental group-strengthening of the activity of only the final stage of the synthesis of glucocorticoid hormone corticosterone with the active release of it in circulation.

As far as the thyroid system is concerned, the stimulation of thyroxin (T4) production can be noted in the thyroid in rats of both experimental groups that in the animals of the 2nd experimental group is also accompanied by an increase in the content of $\mathrm{T} 4$ in the blood serum. Increase in the mass of the thyroid (Table 2) was also noted, and it also speaks about its intensive functioning. At the same time in the animals from the 1st experimental group, the T4 in blood serum does not practically change, however, the level of triiodothyronine (tor) is reduced, which indicates the active spending of thyroid hormones on the background of the general stimulation of metabolic processes. Hence, we can say that enable adaptive reserves of the organism, caused by changes in the hormonal regulation of metabolism and physiological reactions, occur under the influence of both influences, but the animals from the 1st experimental group restructuring is mainly katatoxic, and for the rats of the 2nd group is mainly of the syntactic nature. The volatile nature of the adaptive reactions also says about the rate of body mass change in the dynamics of the experiment; as for the rats of the 1st experimental group, there was a trend to a greater, and the 2nd experimental group to a smaller increase of the body mass.

Table 2 The relative weight of the internal organs of the animals of the control and experimental groups (M $\pm \mathbf{m})$.

\begin{tabular}{|c|c|c|c|c|}
\hline \multirow{3}{*}{ Parameter } & \multicolumn{3}{|c|}{ The group of animals } & \multirow{3}{*}{$\begin{array}{l}\text { Statically significant } \\
\text { differences between } \\
\text { groups, } P<0.05\end{array}$} \\
\hline & \multirow{2}{*}{$\begin{array}{l}\text { The } 1 \text { experiment group } \\
1\end{array}$} & \multirow{2}{*}{$\begin{array}{l}\text { The } 2 \text { experiment group } \\
2\end{array}$} & \multirow{2}{*}{$\begin{array}{l}\text { The control group } \\
3\end{array}$} & \\
\hline & & & & \\
\hline Weight gain, g & $139 \pm 4$ & $127 \pm 4$ & $133+4$ & $1-2$ \\
\hline Heart, g/100g of body mass & $0.31 \pm 0.02$ & $0.31+0.01$ & $0.32 \pm 0.01$ & \\
\hline Kidney, g/100g of body mass & $0.52 \pm 0.01$ & $0.52 \pm 0.01$ & $0.52+0.01$ & \\
\hline Lien, g/100g of body mass & $0.26 \pm 0.01$ & $0.28 \pm 0.01$ & $0.26+0.02$ & \\
\hline Spermary, g/100g of body mass & $0.97 \pm 0.03$ & $1.00 \pm 0.03$ & $1.1 \pm 0.02$ & \\
\hline Prostate, g/100g of body mass & $0.11 \pm 0.01$ & $0.11+0.005$ & $0.10+0.01$ & \\
\hline Thymus, g/100g of body mass & $0.14+0.01$ & $0.16 \pm 0.01$ & $0.15 \pm 0.01$ & \\
\hline Adrenal glands, g/100g of body mass & $14.00 \pm 0.55$ & $14.49+0.60$ & $13.72 \pm 0.66$ & \\
\hline Thyroid body, g/100g of body mass & $5.19+0.19$ & $5.52 \pm 0.36$ & $4.44 \pm 0.30$ & $1-3$ \\
\hline
\end{tabular}


Measurement of the content in the blood serum of the main metabolites of carbohydrate, lipid and protein metabolism-glucose, triglyceride and cholesterol levels, as well as urea-indicates the activation of metabolic processes in both animals experimental groups with an increase in the serum content of the most easily digestible energy substrate glucose.

We have shown previously that aimed transformation of atoms in the living matter, in phylogenesis and ontogenesis of humans determine evolutionary-genetic code of each individual: with the aging the cells they begin to lose the 13-th fraction of carbon. All the mass-spectrometric studies in 2003-2007 were performed by V.P. Kaznacheev [5]. In the opinion of the famous English explorer Krouz [6], the fractioning of isotopes of lead in many of the kinetic processes is defined by the difference between the velocities of reactions with participation of molecules with different sets of isotopes. Isotopic analysis of fur animals reflects chronological record of the diet, drinking regime and various physical and chemical influences for a specific period of ontogenesis.

The experiment with "hormone-active" holograms had the unique results of special importance. Remote contact with holograms in a period of 30 days has led to a significant increase in the relative content of wool of animals' fraction of carbon 13C; in the experience-22.85\%, in the control-23.11\% (Table $3)$. The average rate of change in $13 \mathrm{C}$ in the experimental group was of 0.23 , while in the control of 0.01 (Fig. 1).

The rate of change of the isotope 13C in the two treatment groups was significantly different (Table 4).

Table 3 The dynamics of the relative isotope content $13 \mathrm{C}(\mathrm{M} \pm \mathrm{m})$ in the control and experimental $(1$ and 2$)$ groups in measurements of 19/09/2007 and 10/19/2007.

\begin{tabular}{llll}
\hline & $19 / 09 / 2007$ & $19 / 10 / 2007$ & $\mathrm{R}$ \\
\hline Control & $-23.01 \pm 0.05$ & $-23.11 \pm 0.10$ & $<0.05$ \\
Experience 2 & $-23.02+0.03$ & $-22.85 \pm 0.04$ & \\
Experience 1 & $-22.92 \pm 0.05$ & $-23.0 \pm 0.06$ & \\
\hline
\end{tabular}

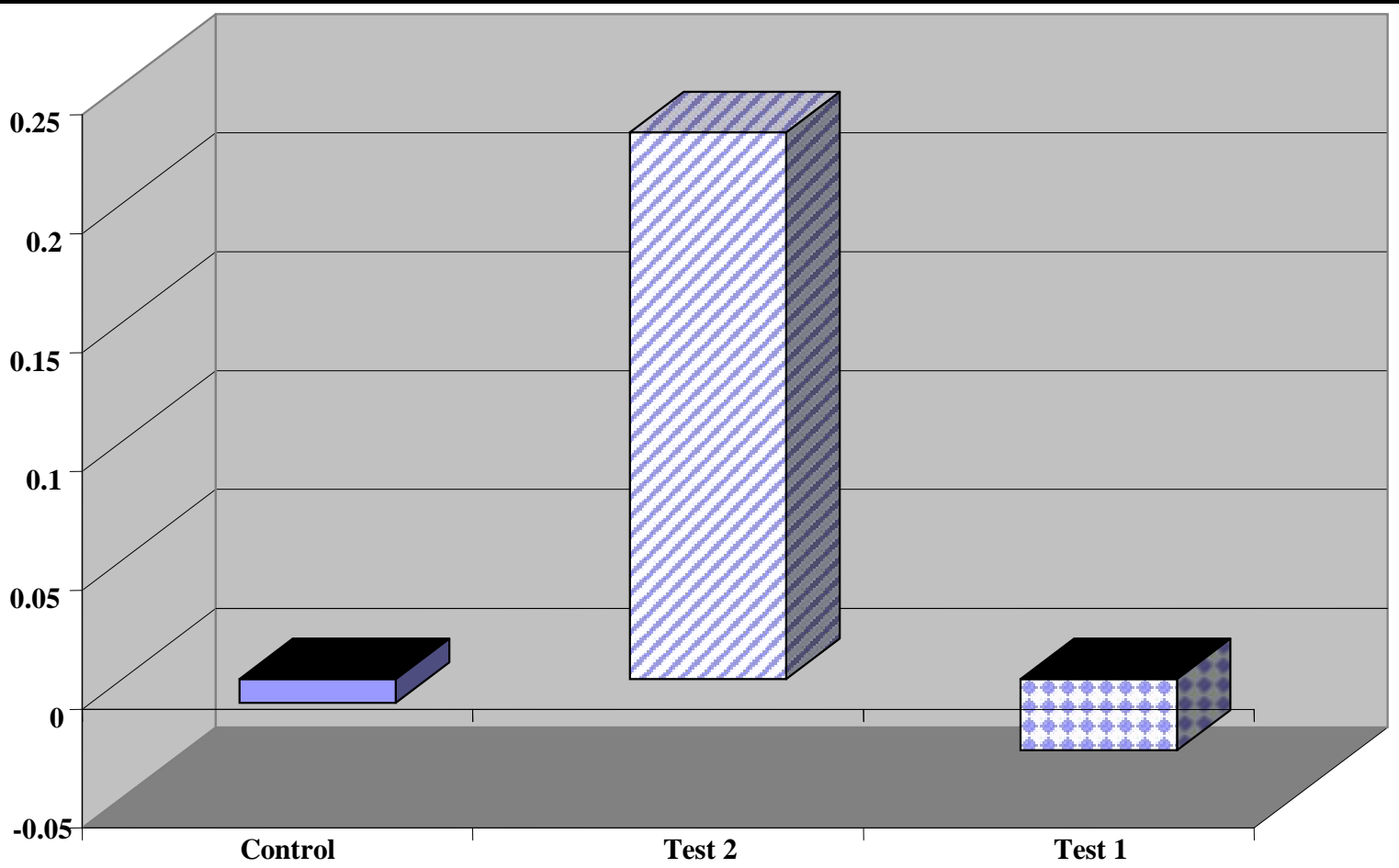

Fig. 1 Changes in the relative values of mean group content of isotope $13 \mathrm{C}$ in the control $(n=10)$ after a 30-day exposure of “hormone-active” holograms water-mediated impact-test $1(n=10)$, and direct remote influence-test $2(n=10)$. 
Table 4 The degree of change (from 19/09/2007 to 19/10/2007) of the relative content of the isotope 13C in the control and experimental ( 1 and 2$)$ groups of rats.

\begin{tabular}{llll}
\hline Control & Experience 2 & Experience 1 & $R$ \\
\hline$-0.49 \pm 0.07$ & $-0.31 \pm 0.05$ & $-0.59 \pm 0.06$ & $P<0.01$ between experience 1 and experience 2 \\
\hline
\end{tabular}

The content of $13 \mathrm{C}$ and its changes in the group of animals that used holographically treated water for drinking did not differ from the control one. But treating water in this way significantly changes the vector and the severity of the dependence of the mass of tissue or organs, i.e. the intensity of protein and synthetic processes of accumulation or loss of isotope 13C: for example, in the experience of $r=-0.64$, in the control -0.55 (adipose tissue); in the experience of $r=$ -0.78 ; in the control of the $r=0$ (the mass of the adrenal glands). Holographic effect in the first scenario leads to a significant change in the functional dependence of the thyroid gland (T4) from the content of isotope 13C: in the experience of $r=0.86$; in the control of the $r=$ -0.50 .

According to the mass spectrometry, at the assessment of stable isotope ratios of carbon 13C/12C in the fur of animals of two groups before and after use for 30 days, the control information of drinking water increases in the heavier isotope $13 \mathrm{C}$ in the experimental group of rats and reduction in the control group was found [7]. That represents a fundamentally important tend for the current project to reduce the speed impact transfer function changes (aging) for about 2 months, which corresponds to 5 years in relation to human ontogeny [8].

Significant changes of correlations between the content of the isotope 13C in the fur of animals and their biochemical, hormonal and morphometric parameters show significant rearrangements in the regenerative processes that occur at the atomic and molecular levels under the influence of holographic broadcast cosmo-hero-tread information [5, 9].

Tables 5-8 show that the "hormone-active" hologram with direct remote and indirect effects of water significantly alters the nature of the functional dependence of the endocrine system, biochemical, metabolic processes, protein synthesis, changes in the mass of individual organs and the whole body in many animals, the intensity of the cosmophysical factors at different stages of the experimental work [9].

In case of remote holographic exposure (in the 2nd experimental group) a direct dependence of the degree of changes in the mass of a body of animals is established, i.e. intensity in the body of protein and synthetic processes, on the intensity of the flow of cosmic rays. It is characteristic that the body weight gained in these animals was lower. In the control $r=$ -0.48 , the AC -0.54; in the experience of $r=0.32$, the AC 0.48. $P<0.05$ in relation depending on body weight gained from the flow of solar protons with energy > $2 \mathrm{MeV}$ (Tables 5 and 6) [9].

When a remote-holographic effects manifested direct significant dependence ( $r=0.48$ ) weights of the seminal vesicles, reflecting the increase in their functional activity, on the intensity of solar protons and

Table 5 Correlations of mass index of rats $(n=10)$ with the protons and electrons of cosmic rays during the control action.

\begin{tabular}{|c|c|c|c|c|c|c|c|c|c|c|c|}
\hline & $\begin{array}{l}\text { Weight } \\
\text { gain }\end{array}$ & Heart & Kidney & Lien & Spermarium & Seminal vesicle & Prostate & Fat depot & Thymus & $\begin{array}{l}\text { Adrenal } \\
\text { glands }\end{array}$ & Thyroid \\
\hline & $\mathrm{g}$ & \multicolumn{10}{|c|}{$1 \mathrm{~g} / 100 \mathrm{~g}$ of body weight } \\
\hline & 1 & 2 & 3 & 4 & 5 & 6 & 7 & 8 & 9 & 10 & 11 \\
\hline $\operatorname{Pr}>1 \mathrm{MeV}$ & -0.54 & -0.21 & -0.34 & 0.53 & 0.06 & -0.48 & -0.32 & -0.36 & -0.15 & 0.20 & 0.26 \\
\hline $\mathrm{Pr}>10 \mathrm{MeV}$ & -0.48 & -0.40 & 0.08 & 0.03 & -0.05 & -0.25 & 0.18 & -0.29 & -0.04 & 0.11 & 0.24 \\
\hline $\operatorname{Pr}>100 \mathrm{MeV}$ & -0.51 & -0.54 & -0.19 & $0.65^{*}$ & 0.31 & -0.51 & -0.58 & -0.23 & -0.16 & 0.03 & 0.23 \\
\hline $\mathrm{El}>0.6 \mathrm{MeV}$ & -0.53 & -0.34 & -0.37 & 0.50 & 0.05 & -0.57 & -0.35 & -0.29 & -0.12 & 0.01 & 0.24 \\
\hline $\mathrm{El}>2 \mathrm{MeV}$ & -0.54 & -0.37 & -0.37 & 0.48 & 0.03 & -0.50 & -0.32 & -0.37 & -0.18 & 0.09 & 0.27 \\
\hline
\end{tabular}

*: significant $P<0.05$ correlation parameters. Pr: protons; El: electrons. 
Table 6 Correlations were mass index of rats $(n=10)$ of the protons and electrons of cosmic rays in the experimental exposure.

\begin{tabular}{|c|c|c|c|c|c|c|c|c|c|c|c|}
\hline & $\begin{array}{l}\text { Weight } \\
\text { gain }\end{array}$ & Heart & Kidney & Lien & Spermarium & Seminal vesicle & Prostate & Fat depot & Thymus & $\begin{array}{l}\text { Adrenal } \\
\text { glands }\end{array}$ & Thyroid \\
\hline & g & \multicolumn{10}{|c|}{ 1g/100g of body weight } \\
\hline & 1 & 2 & 3 & 4 & 5 & 6 & 7 & 8 & 9 & 10 & 11 \\
\hline $\operatorname{Pr}>1 \mathrm{MeV}$ & 0.43 & -0.17 & -0.11 & 0.16 & 0.06 & $0.48 *$ & 0.13 & 0.35 & -0.25 & -0.34 & -0.01 \\
\hline $\operatorname{Pr}>10 \mathrm{MeV}$ & 0.41 & -0.42 & -0.37 & 0.31 & 0.03 & 0.23 & 0.26 & 0.22 & $-0.58 *$ & $-0.64 *$ & -0.32 \\
\hline $\operatorname{Pr}>100 \mathrm{MeV}$ & 0.32 & -0.01 & 0.02 & 0.22 & 0.09 & 0.36 & -0.07 & 0.29 & -0.24 & -0.28 & 0.11 \\
\hline $\mathrm{El}>0.6 \mathrm{MeV}$ & 0.42 & -0.08 & 0.01 & -0.19 & 0 & 0.40 & -0.03 & 0.27 & -0.30 & -0.39 & 0.14 \\
\hline $\mathrm{El}>2 \mathrm{MeV}$ & $0.48 *$ & -0.14 & -0.08 & 0.19 & -0.06 & 0.43 & 0.04 & 0.23 & -0.30 & -0.38 & 0.13 \\
\hline
\end{tabular}

Designations refer to Table 5.

Table 7 Correlations were hormonal parameters in rats $(n=10)$ of the protons and electrons of cosmic rays during the control action.

\begin{tabular}{lllllllll}
\hline Characteristics & $\begin{array}{l}\text { Testosterone } \\
\text { nM/L }\end{array}$ & $\begin{array}{l}\text { T3 in } \\
\text { blood, } \\
\text { nM/L }\end{array}$ & $\begin{array}{l}\text { T4 in } \\
\text { blood, } \\
\text { nM/L }\end{array}$ & $\begin{array}{l}\text { T3 in thyroid, } \\
\text { nmol/mg of } \\
\text { tissue }\end{array}$ & $\begin{array}{l}\text { T4 in thyroid, } \\
\text { nmol/mg of } \\
\text { tissue }\end{array}$ & $\begin{array}{l}\text { Progesterone in } \\
\text { adrenal glands, } \\
\text { nM/mg of tissue }\end{array}$ & $\begin{array}{l}\text { Corticosterone Corticosterone } \\
\text { of plasma, }\end{array}$ & $\begin{array}{l}\text { ng adrenal } \\
\text { glands, ng/mg }\end{array}$ \\
\hline 1 & 2 & 3 & 4 & 5 & 6 & 7 & 8 & 9 \\
$\mathrm{Pr}>1 \mathrm{MeV}$ & 0.19 & 0.14 & 0.43 & 0.13 & 0.14 & 0.32 & -0.20 & -0.04 \\
$\mathrm{Pr}>10 \mathrm{MeV}$ & -0.03 & -0.25 & -0.05 & -0.51 & -0.09 & -0.30 & -0.25 & 0.18 \\
$\mathrm{Pr}>100 \mathrm{MeV}$ & 0.31 & -0.20 & 0.60 & 0.08 & 0.04 & -0.05 & -0.33 & -0.32 \\
$\mathrm{El}>0.6 \mathrm{MeV}$ & 0.14 & 0.10 & 0.47 & 0.10 & 0.20 & 0.18 & -0.19 & -0.03 \\
$\mathrm{El}>2 \mathrm{MeV}$ & 0.25 & 0.13 & 0.38 & 0.11 & 0.16 & 0.23 & -0.27 & -0.04 \\
\hline
\end{tabular}

1, 2, 3, 4, 5 and etc.: Designations in the table. Pr, El: protons and electrons of different energies.

Table 8 Correlations were hormonal parameters in rats $(n=20)$ from the protons and electrons of cosmic rays in the experimental (2) exposure.

\begin{tabular}{lllllllll}
\hline Characteristics & $\begin{array}{l}\text { Testosterone } \\
\text { nM/L }\end{array}$ & $\begin{array}{l}\text { T3 in } \\
\text { blood, } \\
\text { nM/L }\end{array}$ & $\begin{array}{l}\text { T4 in } \\
\text { blood, } \\
\text { nM/L }\end{array}$ & $\begin{array}{l}\text { T3 in thyroid, } \\
\text { nmol/mg of } \\
\text { tissue }\end{array}$ & $\begin{array}{l}\text { T4 in thyroid, } \\
\text { nmol/mg of } \\
\text { tissue }\end{array}$ & $\begin{array}{l}\text { Progesterone in } \\
\text { adrenal glands, } \\
\text { nM/mg of tissue }\end{array}$ & $\begin{array}{l}\text { Corticosterone Corticosterone } \\
\text { of plasma, }\end{array}$ & $\begin{array}{l}\text { of adrenal } \\
\text { glands, ng/mg }\end{array}$ \\
\hline 1 & 2 & 3 & 4 & 5 & 6 & 7 & 8 & 9 \\
Р $>1 \mathrm{MeV}$ & 0.35 & -0.37 & -0.26 & -0.16 & 0.03 & $0.53^{*}$ & 0.31 & $0.61^{*}$ \\
$\mathrm{P}>10 \mathrm{MeV}$ & 0.35 & -0.21 & -0.20 & -0.25 & -0.06 & 0.25 & 0.03 & $0.47^{*}$ \\
$\mathrm{P}>100 \mathrm{MeV}$ & 0.29 & -0.26 & -0.33 & 0.08 & 0.17 & 0.43 & 0.42 & $0.56^{*}$ \\
$\mathrm{El}>0.6 \mathrm{MeV}$ & 0.40 & -0.29 & -0.20 & 0.05 & 0.13 & $0.49^{*}$ & $0.48^{*}$ & $0.67^{*}$ \\
$\mathrm{El}>2 \mathrm{MeV}$ & 0.41 & -0.29 & -0.18 & -0.03 & 0.12 & $0.47^{*}$ & 0.42 & $0.65^{*}$ \\
\hline
\end{tabular}

Designations refer to Table 7.

electrons. In control $r=-0.25+-0.57$; in the experience of $r=0.23-0.48$ (Tables 5 and 6) [9].

When remote-holographic effects are direct correlation values of fat depot that provides regenerative function of animals, the intensity of cosmophysical factors. In the control, $r=-0.23+-0.37$, in the experience of $r=0.23-0.35$ (Tables 5 and 6).

While using the holographically treated drinking water, a significant direct dependence $(P<0.05)$ of weight of the heart, i.e. the severity of synthetic processes in the myocardium, on the intensity of the flow of cosmic rays is set. In the control group $r=-0.21$ $(-0.54)$, in the experience group $r=+0.30 \div(+0.50)$.

In the distance-exposure holographic effect was not observed (Tables 5 and 6) [9].

Experiences in the use of water show a direct dependence of the mass of the kidneys, that is, expressions in these protein-synthetic processes, the intensity of the flux of solar protons and electrons. In the control, $r=-0.19 \div(-0.37)$, in the experience of $r=$ 
$0.22 \div 0.48$. Significant associations $(P<0.05)$ renal masses detected with protons with energies $>1 \mathrm{MeV}(r$ $=0.47$ ) and electrons with energies $>0.6 \mathrm{MeV}$.

In the remote influence holograms this effect that indicates the mechanism of functional systemic exposure holographic treated water to the renal parenchyma (Tables 5 and 6) does not appear

\subsection{The Bioeffect of the Helio-Geroprotective Holograms}

It is shown that the direct impact and hydro-mediated hero-tread, hormone-active information realized through the hologram, significantly changes the nature of the functional dependence of many biological systems cosmo-helio-physical factors (Tables 5 and 8) [9].

There was no such an effect while using the test water. When using for drinking holographically treated water, the effect is increasing and significant direct correlation dependence of mass of the thyroid gland from the intensity of the flow of cosmic rays is set. In the control $r=0.23 \div 0.27$; in the experience $r=0.45 \div$ $0.55(P<0.05)$.

While using remote-holographic water the impact increases and installs a significant inverse relationship between the mass of the thymus, adrenal glands on the intensity of cosmic rays. In the control $r=-0.04 \div$ $(-0.18)$ in (thymus) and $r=-0.11 \div 0.20$ (for adrenal glands); in the experience of $r=-0.25 \div(-0.58)$ (thymus) and $r=-0.34 \div(-0.68)$ (for the adrenal glands). The dependence of the mass of the spleen from galactic protons is reduced 3 times. In the control $r=$ 0.65 , in the experience $r=0.22$ (Tables 5 and 6)[9].

It is proved that we have a new opportunity to change fundamentally the nature and severity of the functional dependence of different biosystems on cosmo-helio-physical factors using helio-herotread holograms. It is shown that by reducing the functional dependence of biosystems heliophysics factors, there is a reduced dependence of the aging process on the size of the solar activity (Tables 7 and 8) [9].

Most of the people whose prenatal development takes place at a minimum of solar activity can reach the heights of longevity.

This phase of the experimental work carried out on animals, shows a unique opportunity: to reduce pressure factors for heliophysics helio-depended people by giving them a unique chance for longevity using holographic solar-hero-protective technology.

During the examination, the mechanisms of the transformation of solar-biosphere connections at the atomic and molecular level were revealed.

\subsection{Effect of Holographic Information on the Dynamics of Isotopy-bio-helio-physical Pairings}

For the first time it was shown that under the influence of cosmo-helio-physical and herotread information available in holograms, the dependence of the content in animals hair of stable isotopes of carbon (13C) on the intensity of galactic and solar corpuscular flows (Tables 9 and 10) (protons, electrons, neutrons) increases when carrying out the experiment changes. For example, in the experience of $1, r=0.57$; in the control , $r=-0.48$ (neutrons) (Table 9). It was reported of the paradox of "advanced" depending on the intensity of $13 \mathrm{C}$ content on cosmic rays within 10 days after the taking hair samples for isotope analysis. In experiment $1 r=0.66$; in control $r=-0.46(P<0.05)$ (with the electrons energy > 0.6 MeV (Table 10) [9].

Table 9 Correlation dependence of the degree of change the relative content of isotope 13C (from September 19 to October 19 2007) on the daily parameters of protons and electrons sunlight for the period from October 10192007.

\begin{tabular}{llllllll}
\hline & $\mathrm{P}_{\Gamma}>1 \mathrm{MeV}$ & $\mathrm{P}_{\Gamma}>10 \mathrm{MeV}$ & $\mathrm{P}_{\Gamma}>100 \mathrm{MeV}$ & $\mathrm{E} 1>0.6 \mathrm{MeV}$ & $\mathrm{E} 1>2 \mathrm{MeV}$ & $\mathrm{Ne} \%$ & $\mathrm{Rad}$ \\
\hline Control & 0.58 & 0.55 & 0.50 & 0.52 & 0.57 & 0.57 & -0.32 \\
Experience 2 & -0.33 & -0.40 & -0.40 & -0.43 & -0.39 & -0.48 & 0.51 \\
Experience 1 & 0.12 & 0.53 & 0.08 & 0.18 & 0.17 & 0.17 & 0.31 \\
\hline
\end{tabular}

Pr: proton; El: The electrons of different energies; Ne\%: neuron; Rad: solar noise. 
Table 10 Correlation dependence of the degree of change the relative content of isotope 13C (from September 19 to October 19 2007) from the daily parameters of protons and electrons sunlight for the period from October 19 to 282007.

\begin{tabular}{llllllll}
\hline & $\mathrm{P}_{\Gamma}>1 \mathrm{MeV}$ & $\mathrm{P}_{\Gamma}>10 \mathrm{MeV}$ & $\mathrm{P}_{\Gamma}>100 \mathrm{MeV}$ & $\mathrm{E} 1>0.6 \mathrm{MeV}$ & $\mathrm{E} 1>2 \mathrm{MeV}$ & $\mathrm{Ne} \%$ & $\mathrm{Rad}$ \\
\hline Control & 0.50 & -0.29 & 0.42 & $0.66 *$ & 0.57 & 0.61 & 0.44 \\
Experience 2 & -0.35 & -0.58 & -0.27 & -0.46 & -0.39 & -0.23 & -0.27 \\
Experience 1 & 0.10 & 0.11 & 0.03 & 0.17 & 0.17 & 0.10 & -0.06 \\
\hline
\end{tabular}

Designations refer to Table 9.

Significantly differences in the control experiments and the dependence of the relative isotope content in wool 13C on the intensity of the proton-electron flows in the period prior to the study and after its completion were noted.

Bio-thermodynamic processes monitored by the ratio in the tissues of stable isotopes of carbon and reflecting the state of atomic and molecular structures of biological systems are an important link in the receptor, of advanced tracking changes in the intensity of cosmic rays $[5,9]$.

\section{Conclusions}

Experimental confirmation of bio-effectiveness of drinking water which passing hypo-geomagnetic and photo-holographic processing in the shielding device "TRODR-1" as solar and magnetic hero tread means changing bio-thermodynamics of body at the atomic and molecular level and it leads to tissue accumulation of stable carbon isotope 13C, positive change vector functional dependence of biosystems on cosmo-physical factors and the increased anabolic, albuminous synthetical processes mean new horizons of preventive medicine [1-9].

Regular use of drinking helio-geo-magnetotreated water in human population with the highest solar-magnetically body will reduce the risk of such helio-depended diseases such as hypertension, coronary heart disease, and many others, and it increases life expectancy [7, 9].

The inclusion of this water into drinking diet of patients with cardiovascular disease will help to prevent their development recessionary conditions and life-threatening complications such as strokes and heart attacks, that often arise during the helio-geomagnetic disturbances (Tables 1, 4, 5 and 8). Thus, there are substantial grounds for belief in the creation of medicineless helio-gero-tread tool that increases the chances of longevity in people with the highest helio-dependence of body which was formed in prenatal ontogeny (Tables 2, 3, 5 and 7) [3, 4, 8, 9].

\section{References}

[1] A.V. Trofimov, The heliogeophysical aspects of circumpolar health/cardiovascular and respiratory diseases, Circumpolar Health 60 (2001) 16-24.

[2] Yu. Burda, A. Trofimov, A. Shabalin, Human organism magnetosensitivity in persons at different age, Advances in Gerontology 20 (3) (2007) 93.

[3] A.V. Trofimov, A.V. Shabalin, Helio-biophysical aspects of geriatry, Advances in Gerontology 20 (3) (2007) 192-193.

[4] A.V. Trofimov, About the possible influence of helio-geophysical factors in prenatal ontogenesis on duration of human life: New horizons of geroprevention, in: Abstract Book of the 6-th European Congress of Biogerontology, Noordwijkerhout, Netherlands, 2008.

[5] V.P. Kaznacheev, A.V. Trofimov, Reflections on Life and Intelligence on the Planet Earth, Problems of Cosmo-Planetary Antropoecology, AFFS Press, Wasserburg, Germany, 2008.

[6] G.P. Krouz Stable isotopes and living systems, Nature 1 (1990) 34-41

[7] A.V. Trofimov, About possibility of delay of organism aging with the use of helio-geroprotectory means, Journal of Nutrition Health and Aging 13 (Suppl. 2) (2009) 17.

[8] A. Trofimov, Impact of the heliophysical factors on man's lifespan in the circumpolar regions: Perspectives of intake of helio-geroprotectors, Circumpolar Health 7 (2010) 356-360.

[9] A.V. Trofimov, G.I. Druzhinin, Information Holograms: Theoretical and Practical Perspectives for the Environment and Medicine of the XXI Century, Polikor Press, Krasnoyarsk, Russia, 2011. 